\title{
Geofluids in Deep Sedimentary Basins and Their Significance for Petroleum Accumulation
}

\author{
Xiaorong Luo, ${ }^{1}$ Zhijun Jin, ${ }^{2}$ Keyu Liu, ${ }^{3}$ and Shuichang Zhang ${ }^{4}$ \\ ${ }^{1}$ Key Laboratory of Petroleum Resources Research, Institute of Geology and Geophysics, Chinese Academy of Sciences, \\ Beijing 100029, China \\ ${ }^{2}$ Petroleum Exploration and Production Research Institute, SINOPEC, Beijing 100083, China \\ ${ }^{3}$ School of Geosciences, China University of Petroleum (East China), Shandong 266580, China \\ ${ }^{4}$ PetroChina Research Institute of Petroleum Exploration \& Development, Beijing 100083, China
}

Correspondence should be addressed to Xiaorong Luo; luoxr@mail.iggcas.ac.cn

Received 11 September 2017; Accepted 19 September 2017; Published 5 December 2017

Copyright (C) 2017 Xiaorong Luo et al. This is an open access article distributed under the Creative Commons Attribution License, which permits unrestricted use, distribution, and reproduction in any medium, provided the original work is properly cited.

\section{Motivation and Background}

Geofluids, including water, liquid, and gaseous hydrocarbons and various nonhydrocarbon gases, not only are the products of geological processes but also actively participate in the geological processes. Understanding geofluids and their interaction with rocks under different geological conditions is fundamental to cognizing the geological processes.

Geofluids may continually flow and circulate underground in rock formations with suitable dynamics and pathways during geological evolution. Therefore the Geofluid Circulation System of Earth (GCSE) not only includes fluids from air, earth surface, and sedimentary basins but also includes fluids derived from deep crust and mantle. However, our understanding of GCSE is quite limited with scarce information because it is difficult to obtain geofluids from the deep crust.

It has been well documented that there exists rich petroleum and mineral resources in deep $(>4500 \mathrm{~m})$ sedimentary formations. Despite the huge cost involved in deep sedimentary basin exploration, thousands of deep wells have been drilled over the past few decades worldwide. By 2014, approximately 1600 deep oil and gas fields had been found in deep sedimentary formations. These discoveries not only have proven that there are huge quantities of petroleum resources in basinal deep formations (BDFs) but also provided rich geological information that enables us to understand much about the properties and phase behaviors of deep geofluids and their chemical reactions with surrounding rock formations, as well as fluid flow and circulations in deep basins. The pioneering researches on geofluids in deep basins reveal a complete new realm, and much of our previous understanding about the geofluids and their evolution based on shallow sedimentary formations might be changed in the near future. They also allow us to better define the key research directions in the basinal geofluid discipline.

\section{Contents of the Special Issue}

The purpose of this special issue is to collate high-quality research articles in deep sedimentary basins. We hope to cover the most recent development on new discoveries, new data, new methodologies, and new understandings on geofluids in deep sedimentary basins and to discuss challenges and opportunities for future resource exploration in deep sedimentary basins.

2.1. Petroleum Generation, Migration, and Accumulation in Deep Sedimentary Basins. With petroleum exploration entering into deep strata, the traditional hydrocarbon generation models seem to confront numerous challenges in explaining the deep hydrocarbon discoveries [1, 2]. Hydrocarbon generation simulation and kinetics research suggested that gases from kerogen cracking could be extended to a relatively higher maturity stage $[3,4]$. It is indicated that although the abundance of long, fatly chains in high-to-over-mature 
kerogen decreases drastically, there is still certain amount of short branched aliphatic structures present, and the lower limit for gas from kerogen cracking can be extended to a maturity stage with Ro reaching 3.5\% [5]. This suggests that high-to-over-mature kerogens in deep and ultradeep strata are still capable of providing material basis for gas generation.

W. Zhao et al. quantitatively reconstructed the yields of light hydrocarbons at different thermal evolution stages and established a set of hydrocarbon expulsion evolution curves for marine organic matters with different TOC values through computing pressurization during hydrocarbon generation and using light hydrocarbon online detection techniques. Based on the oil cracking simulation experiments and kinetics research of different liquid hydrocarbons, they also established a model for probing cracking evolution of different compositions of crude oil and heavy hydrocarbon gas $\left(\mathrm{C}_{2-5}\right)$, as well as in-source and out-source pyrolysis gas generated from liquid hydrocarbons. Their work not only defines the cracking threshold for liquid hydrocarbons with different compositions and occurrences but also quantitatively estimates the contribution of pyrolysis gases to the deep natural gas resources.

Y. Hou et al. discussed the bitumen distribution and maturity in the Devonian carbonate reservoirs in South China. Due to the absence of vitrinite, organic matter maturity can only be obtained by indirect means. Their study found that the oil and gas in the Devonian reservoirs experienced a high temperature of $210^{\circ} \mathrm{C}$ to $260^{\circ} \mathrm{C}$ at the end of Permian, which was a critical period for paleooil reservoir cracking and also a critical period for marine natural gas generation. In combination with the regional tectonic evolution, the maturity of organic matters, which was determined by several techniques, is considered as a key parameter in reconstructing the formation and destruction processes of oil and gas accumulations.

There are multiple sets of hydrocarbon source rocks in the Junggar Basin, Western China, but the main source rocks vary greatly within the basin. Currently there is no consensus on the origin of the Triassic hydrocarbon accumulations in the Central Junggar Basin. M. Wu and coauthors suggested that there were two more sets of source rocks for the Triassic hydrocarbons, in addition to the traditionally perceived Permian source rocks. The Triassic source rocks contributed significantly to hydrocarbon accumulations. The lacustrine Triassic source rock is widely distributed in the Junggar Basin and can generate a significant amount of oil and gas under deep burial, constituting a potential set of effective source rocks. This new understanding further expands the oil and gas resource potential in the deep strata in the Junggar Basin. Based on whole oil carbon isotopes and various biomarker parameters and combined with the linear regression method, $\mathrm{M}$. Wu et al. determined the contribution ratio of various sources rocks.

$\mathrm{X}$. Wu and coauthors used geochemical data of the Upper Paleozoic tight gas in the Hangjinqi area of the Northern Ordos Basin in Western China to study the geochemical characteristics of tight gas. They found that the tight gas is mainly of coal-type and has been affected by mixing of oil-type gas in the wells from the Shilijiahan and Gongkahan zones adjacent to the Wulanjilinmiao and Borjianghaizi faults. Gas-source correlation indicates that the coal-type gas in the Shiguhao zone is typical of a distal-source accumulation, whereas the natural gas in the Shilijiahan and Gongkahan zones is mainly characterized by a near-source accumulation.

\subsection{Petrology and Petrophysics of Deeply Buried Rocks and} Reservoirs. Generally, strata experiencing deep burial in a basin tend to encounter more types of diagenesis and more complex diagenetic processes. Thus, the reservoir porosity and the permeability generally become worse with increasing depths $[6,7]$. The permeability of deeply buried reservoirs is rather low, which are often considered to be tight reservoirs. However, recent oil and gas exploration has revealed that, in the deep strata (below $4500 \mathrm{~m}$ ) or the ultradeep strata (below $6000 \mathrm{~m}$ ), some decent pore space of sedimentary rocks can still be maintained (F. Wang et al. and B. Cao et al.). In some carbonate plays, high porosity-permeability belts can still be present even below $7000 \mathrm{~m}$ to $8000 \mathrm{~m}$ (W. Wei et al.).

B. Cao et al. illustrate the diagenesis processes in the Jurassic formations in the Central Junggar Basin (NW China); ductile lithic-rich, very fine-grained sandstones deposited in all facies associations display compaction of easily deformed, clay-rich grains, resulting in a rapid loss of porosity during the earlier burial phase. They found that ductile lithic-rich, tightly compacted sandstones and calcite completely cemented sandstones can create permeability barriers embedded in permeable reservoir sandstones, resulting in heterogeneous flow. Especially when reservoirs come in contact with petroleum during the burial process, petroleum is prone to migrate and accumulate in rocks with better physical properties between barriers. The flux of oil and gas in reservoirs would alter the diagenetic environment, which may impede or terminate the diagenesis. The presence of late diagenetic calcite and sulphate cements is a good mineralogical indicator of oil charge and migration. Therefore, in different parts of the same reservoir, differential diagenetic discrepancy would be enhanced, which causes larger anisotropy in BDFs reservoir.

In tight clastic reservoirs, J. Lai et al. found two diagenetic stages of carbonate cements. The early diagenetic stage corresponds to a shallow burial with carbonate cements being pore-filling and grain-replacing calcite and dolomite. A late diagenetic stage occurred at a mesogenetic deepburial depth with carbonate cements appearing as ferroan calcite and ferroan dolomite replacing framework grains and precipitating in intergranular pores.

B. Cao et al. regarded this to have been caused by different sedimentary facies, characterized by different reservoir particle sizes, granular components, and depositional structures. Various authigenic minerals with predominately patchy texture, including calcite, clays, analcime, anhydrite, barite, quartz overgrowth, and albite, are present in the fine-grained lithofacies deposited principally in fluvial channel, distributary channel, and distributary-mouth bar facies. Chlorite coats only occur in the distributary channel and distributarymouth bar facies, whereas analcime and illite/smectite clays are most common in the fluvial channel facies. Hematite rims only occur in the fluvial channel facies. 
W. Wei et al. investigated the diagenetic processes and porosity development tied to fault-controlled hydrothermal fluids in the deep Cambrian dolomite reservoirs in the ultradeep borehole TS1 ( 8408 $\mathrm{m}$ deep) in the Tarim Basin. Their studies focused on the critical diagenetic processes and their roles in pore generation and plugging. They present some prevalence evidence of dissolved, less-cemented open vugs in the deeper part of a well in the northern Tarim Basin and demonstrated that these pores and vugs were formed in association with fault-channeled hydrothermal fluids from greater depths.

\subsection{Fluid Flow and Circulation in Deep Sedimentary Basins.} In sedimentary basins associated with deep hot fluids, the heat transmitted can also cause thermal alteration of the oil, thus forming "hydrothermal" oil which may not be consistent with the typical "thermogenic" oil $[8,9]$. The Fischer-Tropsch reaction, considered to be a common inorganic chemical reaction in geothermal systems and ultrabasic rocks $[10,11]$, can produce the precursors of the critical organic molecules required for hydrocarbon generation. Fischer-Tropsch synthesis has been known to occur widely in deep hot fluid intrusion areas [12]. Under high temperature and pressure in the lower crust-upper mantle, considerable amounts of hydrocarbons of inorganic origin may be present. These hydrocarbons may be brought into basins via deep fluids to form reservoirs [13]. In addition, deep fluids are rich in $\mathrm{CO}_{2}$ and Helium, which are likely to be preserved in the deep parts of basins so as to form important natural gas resources [1416].

J. Li et al. construct a mutual solubility model to simulate the chemical reaction processes in $\mathrm{CO}_{2}-\mathrm{CH}_{4}$-brine systems under a wide range of temperatures $\left(0-250^{\circ} \mathrm{C}\right)$, pressure (1-1500 bar), and salinity ( $\mathrm{NaCl}$ molality from 0 to more than $6 \mathrm{~mole} / \mathrm{kgW}$ ). The result demonstrates that, in a deep basinal setting, calcite can be more stable than dolomite; and with the presence of $\mathrm{CH}_{4}$ and $\mathrm{H}_{2} \mathrm{~S}$ in the gas phase, hydrocarbons tend to become "soured."

J. Liu et al. document the origin of diagenetic fluids of a deeply buried carbonate reservoir in the Tarim Basin in NW China by using a combination of petrology, in situ Secondary Ion Mass Spectrometry (SIMS) analysis, fluid inclusion analysis, and radiogenic isotope analysis of pore-filling calcite cements. The multiple cement stages produced poor matrix porosity, whereas caves and fractures formed during epigenetic karstification constitute the dominant reservoir spaces. A corresponding diagenesis-related reservoir evolution model was established which favors exploration and prediction in deeply buried reservoir in the Tahe area.

The pore fluid evolution of the Paleogene medium-deep reservoirs in the Huanghekou Sag of the Bohai Bay Basin in China was investigated by Z. Sun et al. The authors demonstrated that volcanic activities may exert a significant influence on the pore fluid properties depending on the volcanic activity intensity. The evolution of pore fluids can be divided into three stages corresponding to volcanic activities. The vertical distribution of pore fluids with varied properties in different intervals controls the diagenetic processes and reservoir quality.
Organic fluids have an obvious effect on diagenesis. J. Lai et al. observed that the content of carbonate cement has good correlation with its distance to the source rock. They believed that the dissolution of Ca-feldspars by organic acidrich fluids together with clay mineral transformations such as illitization of smectite would provide $\mathrm{Ca}^{2+}$ and $\mathrm{Mg}^{2+}$ ions for carbonate cementation. Organic acids and $\mathrm{CO}_{3}{ }^{2-}$-rich fluids would charge into reservoirs together with hydrocarbons. When $\mathrm{CO}_{2}$ and acids were buffered by the framework grain dissolution, carbonate cements would precipitate, causing a decrease in $\mathrm{CO}_{2}$ concentration.

\subsection{Methodologies for Understanding Geofluids in Basinal} Deep Formations. Data for geofluids in BDFs are quite scarce overall due to limited drilling, challenging environments, and high sampling cost [17]. Recent observation, measurements, and laboratory physical simulations indicate that there do not appear any fundamental differences in the ways of fluidrock interactions between the deeply buried formations and their shallow counterparts $[6,18]$. Therefore, some of the conventional simulation algorithms developed for shallow reservoirs can be used to simulate fluid-rock interaction in BDFs with elevated pressures and temperatures.

As demonstrated by papers in this special issue, the main methodologies commonly used for studying geofluids in sedimentary basins are similar to those used for shallow reservoirs including (1) analyzing natural analogues, (2) physical simulation in the laboratory, and (3) numerical simulations.

The reservoir rocks in deep basin tend to become tighter [7]. The accurate measurements of permeability of ultralow permeability rock are imperious for reservoir quality evaluation. Y. Guo et al. proposed a new transformation model between the NMR transverse relaxation time and the relative permeability of the wetting phase, where a piecewise method was used to calculate relationship between the transverse relaxation time and relative permeability. The authors also demonstrated a way to determine the piecewise points by the mutation position of the fractal dimensions, with pore radius ranges of $0.03 \mu \mathrm{m}$ and $1 \mu \mathrm{m}$ in their case. The method provided a theoretical basis for interpreting relative permeability curve with depth through the NMR logging data.

The works of S. Liu et al. and H. Zhu et al. presented two case studies of BDFs in the Sichuan Basin and the Tarim Basin, respectively. Both works are on the Paleozoic carbonate petroleum systems that are currently under active exploration. S. Liu et al. illustrate an effective basin analysis technique for investigation of BDFs and corresponding petroleum systems, while $\mathrm{H}$. Zhu et al. demonstrate how new seismic interpretation techniques and procedures can help identify reservoir sweet spots or zones in BDFs.

The experimental work by $\mathrm{Z}$. He et al. provided some new insights into carbonate dissolution in BDFs. Through laboratory experiments and field observation, they concluded that high poroperm carbonate reservoirs in BDFs would require an open or semiopen fluid system in the subsurface with the types of formation water primarily determining the dissolution capability, whereas close fluid systems can only preserve preexisting reservoir spaces. 
J. Li et al. present a mutual solubility model for $\mathrm{CO}_{2}{ }^{-}$ $\mathrm{CH}_{4}$-brine systems under high pressure and temperature (up to $250^{\circ} \mathrm{C}$ and $150 \mathrm{MPa}$ ), which is applicable to BDFs. By combining with the PHREEQC functionalities, they computed the $\mathrm{CO}_{2}-\mathrm{CH}_{4}$-brine-carbonate-sulfate equilibrium and concluded that, for $\mathrm{CO}_{2}-\mathrm{CH}_{4}$-brine-carbonate systems in $\mathrm{BDF}$, magnesium is more likely to be dissolved in aqueous phase, while calcite could be more stable than dolomite.

W. Wei et al. investigated the diagenetic processes and porosity development based on the petrographic investigation and petrophysical data integrated with fluid reactive transport modeling using TOUGHREACT. Their modeling results indicate that pores and vugs may be effectively formed in the deeply buried dolomites associated with faults, where hydrothermal fluids flow upward from deeper formations.

\section{Acknowledgments}

We are grateful to all the authors for their great contributions to this special issue and for their dedication and perseverance during the revision process. We are indebted to the 60 or so reviewers who helped evaluate and improve those papers.

\section{Xiaorong Luo Zhijun Jin Keyu Liu Shuichang Zhang}

\section{References}

[1] F. Behar, S. Roy, and D. Jarvie, "Artificial maturation of a Type I kerogen in closed system: Mass balance and kinetic modelling," Organic Geochemistry, vol. 41, no. 11, pp. 1235-1247, 2010.

[2] K. He, S. Zhang, J. Mi, and G. Hu, "The speciation of aqueous sulfate and its implication on the initiation mechanisms of TSR at different temperatures," Applied Geochemistry, vol. 43, pp. 121-131, 2014.

[3] A. S. Pepper and P. J. Corvi, "Simple kinetic models of petroleum formation. Part I: oil and gas generation from kerogen," Marine and Petroleum Geology, vol. 12, no. 3, pp. 291-319, 1995.

[4] N. Mahlstedt and B. Horsfield, "Metagenetic methane generation in gas shales I. Screening protocols using immature samples," Marine and Petroleum Geology, vol. 31, no. 1, pp. 2742, 2012.

[5] J. Mi, S. Zhang, J. Chen et al., "Upper thermal maturity limit for gas generation from humic coal," International Journal of Coal Geology, vol. 152, pp. 123-131, 2015.

[6] S. Bloch, R. H. Lander, and L. Bonnell, "Anomalously high porosity and permeability in deeply buried sandstone reservoirs: Origin and predictability," AAPG Bulletin, vol. 86, no. 2, pp. 301-328, 2002.

[7] S. N. Ehrenberg and P. H. Nadeau, "Sandstone vs. carbonate petroleum reservoirs: A global perspective on porosity-depth and porosity-permeability relationships," AAPG Bulletin, vol. 89, no. 4, pp. 435-445, 2005.

[8] R. C. Burruss and C. D. Laughrey, "Carbon and hydrogen isotopic reversals in deep basin gas: Evidence for limits to the stability of hydrocarbons," Organic Geochemistry, vol. 41, no. 12, pp. 1285-1296, 2010.
[9] B. R. T. Simoneit, "Petroleum generation, an easy and widespread process in hydrothermal systems: an overview," Applied Geochemistry, vol. 5, no. 1-2, pp. 3-15, 1990.

[10] T. M. McCollom and J. S. Seewald, "A reassessment of the potential for reduction of dissolved $\mathrm{CO} 2$ to hydrocarbons during serpentinization of olivine," Geochimica et Cosmochimica Acta, vol. 65, no. 21, pp. 3769-3778, 2001.

[11] Q. Fu, B. Sherwood Lollar, J. Horita, G. Lacrampe-Couloume, and W. E. Seyfried Jr., "Abiotic formation of hydrocarbons under hydrothermal conditions: Constraints from chemical and isotope data," Geochimica et Cosmochimica Acta, vol. 71, no. 8, pp. 1982-1998, 2007.

[12] E. M. Galimov, "Isotope organic geochemistry," Organic Geochemistry, vol. 37, no. 10, pp. 1200-1262, 2006.

[13] X. Wang, Z. Ouyang, S. Zhuo, M. Zhang, G. Zheng, and Y. Wang, "Serpentinization, abiogenic organic compounds, and deep life," Science China Earth Sciences, vol. 57, no. 5, pp. 878887, 2014.

[14] J. X. Dai, J. Li, W. W. Ding et al., "Geochemical characters of the giant gas accumulations with over one hundred billion cubic meters reserves in China," Petroleum Exploration and Development, vol. 32, no. 4, pp. 16-23, 2005.

[15] J. Wang, W. H. Liu, J. Z. Qin, J. Zhang, and B. J. Shen, "Reservoir forming mechanism and origin characteristics in Huangqiaocarbon dioxide gas field, North Jiangsu Basin," Natural Gas Geoscience, vol. 19, no. 6, pp. 826-834, 2008.

[16] Q. Y. Liu, J. X. Dai, Z. Y. Jin et al., "Abnormal hydrogen isotopes of natural gases from the Qingshen gas field, the Songliao Basin," Geochimica, vol. 43, no. 5, pp. 460-468, 2014.

[17] Z. Li, "Research frontiers of fluid-rock interaction and oilgas formation in deep-buried basins. bulletin of mineralogy," Petrology and Geochemistry, vol. 35, pp. 807-816, 2017.

[18] C. Fan, Z. Wang, A. Wang et al., "Identification and calculation of transfer overpressure in the northern Qaidam Basin, northwest China," AAPG Bulletin, vol. 100, no. 1, pp. 23-39, 2016. 

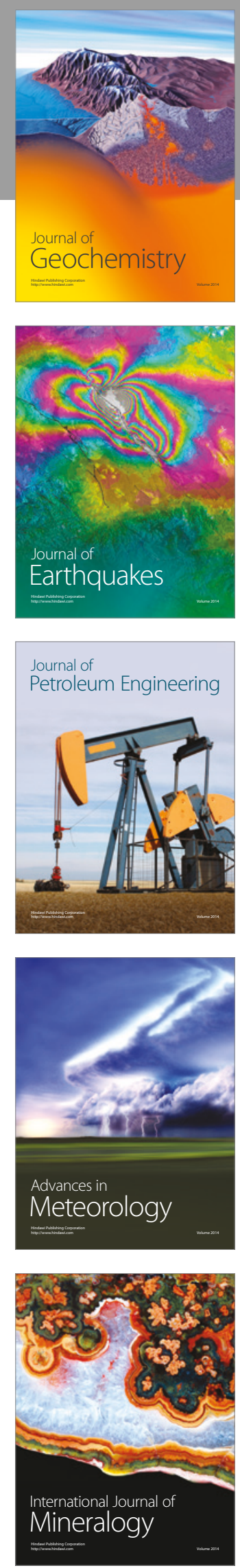
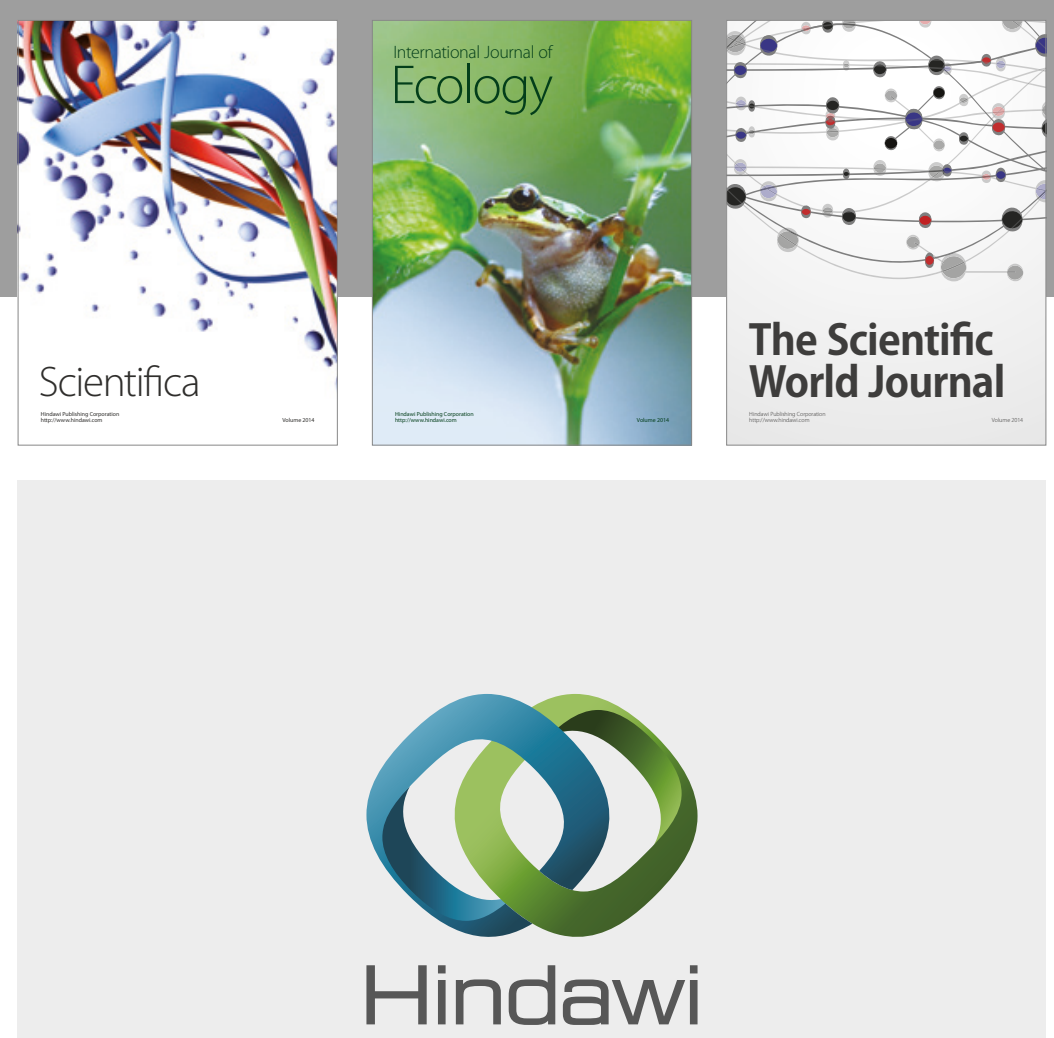

Submit your manuscripts at

https://www.hindawi.com
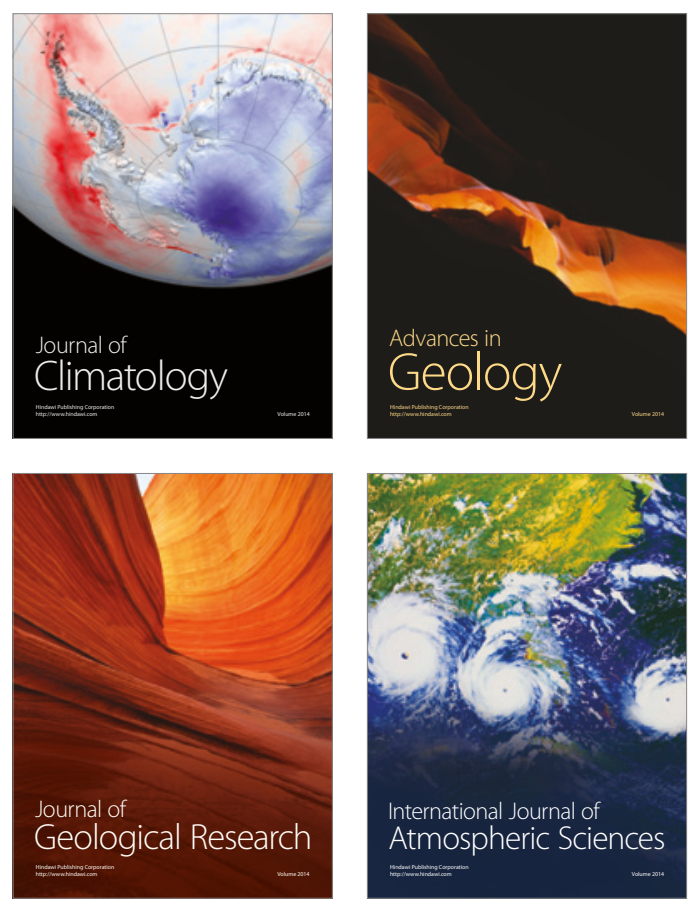

The Scientific

World Journal
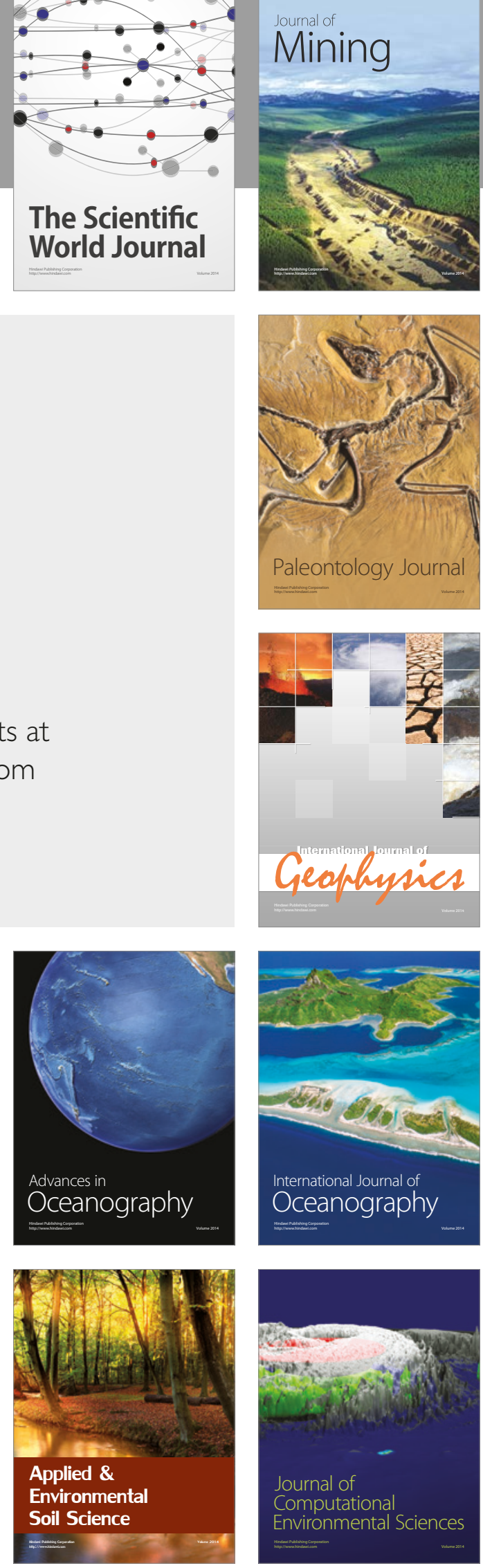